\title{
Pick up an oar - or swab - and row
}

\author{
Miriam I Redleaf ${ }^{1 *}$, Julia L Kerolus ${ }^{2}$, Margaret Mary Fahey Graf ${ }^{3}$ and Marc De Var ${ }^{4}$ \\ ${ }^{1}$ Director of Otology, Neurotology and Global Otology, Department of Otolaryngology/Head and Neck Surgery, University of Illinois Hospitals, USA \\ ${ }^{2}$ Director Facial Nerve Services, Department of Otolaryngology/Head and Neck Surgery, University of Illinois Hospitals, USA \\ ${ }^{3}$ Director UI Health Revenue, Patient Accounting, South Marshfield Avenue, USA \\ ${ }^{4}$ Associate Chief Financial Officer, UI Health Revenue Cycle Services, South Marshfield Avenue, USA
}

*Corresponding author: Miriam I Redleaf, Director of Otology, Neurotology and Global Otology, Department of Otolaryngology/Head and Neck Surgery, University of Illinois Hospitals, Chicago, USA.
Received Date: April 16, 2020

Published Date: April 28, 2020

\section{Opinion}

On the morning of Thursday March 26, 2020 one of us, a facial plastics surgeon at the University of Illinois Department of Otolaryngology/Head and Neck Surgery, noted that COVID-19 nasopharyngeal swabs in the US were showing a very high false negative rate. She suggested this may be due to obtaining specimens from the septum and anterior portions of the turbinates, rather than the nasopharynx. In the afternoon, our department formed a swab education team, and another of us, our head neurotologist at the University of Illinois, was assigned as lead. As the two doctors were gathering information, we were approached on Friday, March $27^{\text {th }}$ to also plan how we might help University Health Services accommodate the increase of COVID-19 related employee visits.

Therefore, during the week of March $30^{\text {th }}$ through April $3^{\text {rd }}, 2020$ the two otolaryngology subspecialists demonstrated nasopharyngeal swabbing to 12 sessions of healthcare workersspeaking and answering questions to $10-20$ people at a time. At the end of the week we made an educational video [1] which we posted on our health systems' internet. The educational efforts were greatly appreciated by the hospital staff-in each of the 12 sessions, several nurses or doctors spoke up and stated that they were surprised how deep the nasopharynx was.

Meanwhile, two experienced administrators worked through the logistics of creating a high-turnover COVID testing site for our employees. By April $1^{\text {st }}$, they had found open clinical space and cleaned it and converted it. By April $2^{\text {nd }}$ they had arranged an orientation session in the morning-complete with phone registration, patient lists, fit testing, one receptionist, two medical assistants, two medical student volunteers, one manager, and two security officers to safely route the patient traffic. Our first employee testing began in the afternoon with a limited schedule. On Friday, April $3^{\text {rd }}$, we had our first full schedule morning clinic with 2 ENT doctors performing the swabs. The second week of swabbing processed $43,44,62,84$, and 53 patients in 2-3 hours each morning. The University Health Services and the University employees have repeatedly expressed their thanks for the services and their satisfaction with how efficient and painless the entire process was.

We have thought about what features of this experience have made it so successful. One was that all the organizers were willing to perform tasks which they knew well how to do, but were "beneath them." Otolaryngology subspecialists were immediately willing to demonstrate the lowly nasal swab over and over to groups of other healthcare professionals. Otolaryngologists who normally interpret specialized tests and perform complex operations pitched in-two at a time-every morning to swab dozens of fellow employees in a few hours. Administrators who no longer work "in the trenches" put aside their business analyses and revenue investigations and assembled a functioning clinic in two days. Everybody just picked up an oar-or nasopharyngeal swab-and rowed.

Another feature we uncovered is that, the joy of a light work day, and avoiding work altogether is a myth. Everyone working in the testing clinic-stated that they greatly enjoyed working full tilt without any down time. They never had to wait and they were never bored. Finally, despite the lowly task, everyone felt extreme satisfaction that they were doing something helpful-a task that was really needed. 
The major early lessons from this experience are rather inspiring. First is that healthcare workers truly want to help others. Second is that many of the administrative procedures which hobble healthcare delivery in fact turn out to be dispensable. And third is that otolaryngologists love to work, and want to work hard and efficiently. In this age of increasing paperwork and computer clicks, COVID has shown that it is possible to get back to basics-healthcare.

\section{Acknowledgement}

None.

\section{Conflict of Interest}

No conflict of interest.

\section{Reference}

1. https://drive.google.com/file/d/1U8RovwSWxEMXf8rsjnxd7MchvTBQ tUbM/view 